Boise State University

ScholarWorks

Psychological Sciences Faculty Publications and

Presentations

Department of Psychological Science

9-1-2010

\title{
Comparing Narratives of Personal and Preferred Partner Characteristics in Online Dating Advertisements
}

\author{
Elizabeth M. Morgan \\ Boise State University \\ Tamara C. Richards \\ Boise State University \\ Emily M. VanNess \\ Boise State University
}

\section{(c) $\oplus \Theta \Theta$}




\title{
Comparing Narratives of Personal and Preferred Partner Characteristics in Online Dating Advertisements
}

\author{
Elizabeth M. Morgan, Tamara C. Richards, and Emily M. VanNess \\ Boise State University
}

\begin{abstract}
This study explored online personal ads of 294 heterosexual and homosexual men and women in the United States through a qualitative analysis and comparison of participant-generated "personal” and "preferred partner" narratives. Nine characteristics were identified and combined into three overarching categories: physical, lifestyle, and personality characteristics. These three personal and preferred partner characteristics were examined for difference by gender, sexual orientation, age and desired relationship type of the advertisers. Main effects emerged for all four predictors, most notably for age and desired relationship type. Additionally, this study explored the possibility that personal and preferred partner narratives contained similar constellations of characteristics, finding significant correlations on all three variables, lending support for the matching hypothesis in dating partner characteristics.
\end{abstract}

Keywords: Internet dating, gender differences, mate preferences, initiation of personal relationships

Technological innovations over the past ten years have produced a steep increase in the use of online dating websites, which have provided an efficient avenue for individuals seeking many different kinds of companionship (Gibbs, Ellison, \& Heino, 2006; Hardey, 2004; Ellison, Heino, \& Gibbs, 2006). Indeed, it has been estimated that over 20 million individuals access online dating websites every month (Online Dating Magazine, 2007) and that about half of adults in the United States report knowing at least one person who has dated someone they met online (PRWed.com, 2009). Diverse options of dating websites are available, based on special interests, orientations, and geographies (Arvidsson, 2006). These websites often allow participants to search for romantic partners based on demographic and personal characteristics such as gender, sexual orientation, age, ethnicity, religious affiliation, education, hobbies, and many other desired attributes. They provide fertile ground for romantic and sexual identity construction, as individuals are able to select and generate an almost unlimited amount of information to share with and request from potential romantic partners.

As such, examining the content of personal ads is one way to determine what characteristics men and women purport to desire in romantic partners and what they believe others desire in them (Gonzales \& Meyers, 1993). Indeed, Jagger (2005) stated that "dating advertisements are a revealing site for examining the social construction of identities - identities that are deemed desirable and marketable in a specific cultural context and constituted in normative (hetero)sexuality” (p. 90). Additionally, while it may be argued that online dating profiles are rife with lies and exaggerations, research indicates that online advertisers are actually dually interested in presenting desirable and realistic portrayals of self (Toma, Hancock, \& Ellison, 2008; Whitty, 2008). Despite the proliferation of online dating websites and rich data they offer, only a handful of studies examine how online advertisers represent themselves and what they see as desirable attributes to further our understanding of contemporary romantic and sexual identities (e.g., Ellison, Heino, \& Gibbs, 2006; Jagger, 2001; Gibbs, Ellison, \& Heino, 2006) and few studies have compared offered and requested characteristics in personal ads (e.g., Harrison \& Saeed, 1977; Cicerello \& Sheehan, 1995).

The present study extends past research examining the personal characteristics of individuals in the United States posting personal ads through a qualitative analysis and comparison of participant-generated "personal narratives" and "preferred partner narratives". More specifically, the examination will provide information regarding how young adults chose to present themselves as desirable dating partners, which characteristics they outline as desirable 
in others, and how these characteristics might differ based on demographic variables and desired type of relationship. Additionally, by examining both personal and preferred partner narratives simultaneously, we are able to explore whether individuals tend to indicate wanting similar or divergent characteristics in their romantic partners. The new approach of making use of participant-generated narratives will offer a more nuanced examination of romantic and sexual identity construction than previous studies of online dating ads, which made use of information participants selected from a list of available options on the dating website.

\section{Content Analyses of Personal and Preferred Partner Characteristics}

Content analyses of personal ads typically examine profile characteristics selected from predetermined lists and then compare these characteristics based on the participants' gender or sexual orientation. Regarding gender differences in heterosexual adults' ads, past research has found that men's personal profiles are more likely to offer physical descriptors, expressive qualities, and career, education, and financial status while women more often offer physical attractiveness and instrumental qualities (Cicerello \& Sheehan, 1995; Koestner \& Wheeler, 1988). Regarding preferred partner characteristics, men are more likely to request an attractive, shorter, younger partner with expressive qualities, while women often request taller, older partners with more advanced career and educational status (Bollig, Stein, \& McKenry, 1984; Cicerello \& Sheehan, 1995; Jagger, 2005; Kenrick, Keefe, Bryan, Barr, \& Brown, 1995; Koestner \& Wheeler, 1988; Matthews, 1999; Rajecki, Bledsoe, \& Rasmussen, 1991). Koestner and Wheeler (1988) also found that men were more likely to mention their height and request weight from potential partners, while women were more likely to mention their weight and request height in return. Overall, Jagger (2001) found that men held somewhat more varied presentations of self in personal ads than did women, whose profiles primary features included physical attractiveness and sexuality.

Research has also emphasized self-presentation differences based on sexual orientation, offering examinations of gay men and women's ads along with comparisons to their heterosexual counterparts. Gonzales and Meyers (1993) found that, overall, heterosexuals were more likely to pursue long-term relationships and mention personal sincerity and financial security in print ads while homosexuals were more likely to emphasize personal and preferred physical characteristics and sexuality. Most of this research has shown that gender and sexual orientation interact to produce differences in personal and preferred partner characteristics outlined in the advertisements. For example, Child, Low, McCormick, and Cocciarella (1996) found that homosexual men mentioned sexuality and physical characteristics more often while heterosexual men offered financial security and occupational status. Heterosexual women also tend to provide and request physical descriptors more than lesbians (Gonzales \& Meyers, 1993; Smith \& Stillman, 2002). Additionally, when comparing homosexual men and women's ads, men more often emphasize sexual and physical attractiveness while women emphasize emotional and personality characteristics (Hatala \& Prehodka, 1996; Thorne \& Coupland, 1998).

Several other studies have explored demographic differences in personal and preferred partner characteristics other than gender and sexual orientation. For example, a content analysis of older adults' advertisements revealed an emphasis on nonsexual relational goals and few references to age (Coupland, 2000). In addition, Jagger (2005) found that younger men and older women were the most likely to advertise and that men were more likely to mention their age in ads than women. Few studies to date have examined differences in preferences based on the types of relationship requested. Buunk, Dijkstra, Fetchenhauer and Kenrick (2002) found that individuals who were interested in a lower level of involvement (i.e. casual sex, sexual fantasies) preferred partners who were more physically attractive and were less concerned with education levels. As involvement levels increased (i.e. serious relationship, marriage) individuals preferred partners with higher self confidence.

In summary, content analyses have established patterns based on gender and sexual orientation regarding a limited number of characteristics present in personal ads, along with a handful of other demographic characteristics. Because much of this research was conducted with print ads and was limited in the characteristics examined, the first goal of this study is to extend this body of research by assessing a broader array of personally-narrated characteristics based on demographic factors and desired relationship type. 


\section{Comparing Personal and Preferred Partner Characteristics}

In addition to exploring contemporary romantic and sexual identities and preferred partner characteristics in young adults' online personal ads, the present study explores how often the personal characteristics described in online ads are mirrored in preferred partner narratives. The role of similarity in romantic relationships has been wellestablished through research on assortive mating and the matching phenomenon/hypothesis. Overall, research indicates that similarity is much more common in romantic relationships than complementarity (e.g., holding different or opposite characteristics), though stronger similarity was found in age, religiousness, and education, and weaker associations were found regarding personality (Watson, Klohnen, Casillas, Nus Simms, Haigh, \& Berry, 2004). Several researchers have explored this phenomenon as it relates to dating advertisements, findings that people seek an equivalent exchange by offering and requesting matching credentials in their personal ads (Harrison \& Saeed, 1977; Miller, Smith, \& Trembath, 2000; Rowat, Cunningham, \& Druen, 1999). For example, Harrison and Saeed (1977) discovered that people sought partners with similar levels of social desirability and attractiveness as themselves. In a study reviewing body size requests in personal advertisements, Miller, Smith and Trembath (2000) found that heavier women were less stringent of prospective partners' weight. Research also shows that individual posting personal ads may attempt to become more attractive to potential partners by matching their physical features and personality type to their prospective partners' physical features and personality type (Rowat, Cunningham, \& Druen, 1999).

As outlined above, analyses of dating advertisements often reveal patterns of offered and requested characteristics that vary based on the individuals' gender (e.g., Koestner \& Wheeler, 1988). Frequently conducted with heterosexual individuals, analyses of dating ads suggest a divergence in which characteristics are most important for male partners (e.g., status) and female partners (e.g., attractiveness). However, in another study, Cicerello and Sheehan (1995) found that men typically offered traditionally feminine emotion-based traits while women typically offered traditionally masculine traits in dating profiles. These findings can be interpreted as supporting the matching hypothesis because male and female profilers might have assumed a proper relational exchange was only feasible when the characteristics they desired in potential mates were also personally required characteristics.

In summary, while general research on romantic relationships indicates that similarity wins out over difference, little is known about whether the characteristics individuals present and request in dating advertisements tend to converge or diverge. Furthermore, while research generally finds that heterosexual men and women tend to offer and request complementary gender-based characteristics in dating advertisements, contemporary within-subject examinations with both heterosexual and sexual minority individuals are lacking.

\section{The Present Study}

The goals of the present study were to examine the personal characteristics and preferred partner characteristics outlined in online dating advertisement narratives by young adults in the United States. The first goal was to assess the frequency with which different personal characteristics were mentioned in "personal narratives" and "preferred partner narratives" written by the dating website participant. Because few studies examine narratives, instead analyzing pre-selected demographic, personality, and lifestyle variables, we expect this analysis to provide additional insight into the romantic and sexual identity construction present in online dating advertisements.

The second goal was to examine the roles of gender, sexual orientation, and age on the characteristics outlined in personal narratives and preferred partner narratives. Based on past research, we expected differences based gender and sexual orientation - the two most frequently examined variables in personal ads. Next, we were interested in examining how the participants' desired relationship type related to the characteristics outlined in the personal narrative and preferred partner narrative. Again, since past research has suggested some differences based on relationship type (Buunk et al., 2002), we expected several to emerge in this study.

Lastly, the present study examined the congruence between the characteristics outlined in participants' personal narrative and those outlined in their preferred partner narratives. Based on research on romantic relationship matching in domains other than online dating advertisements (Bolig, Stein, \& McKenry, 1984; Gonzales \& Meyers, 1993; Rajecki, Bledsoe, \& Rasmussen, 1991), we would expect substantial similarity regarding most of the characteristics. 


\begin{abstract}
Method
Participants

Online dating advertisements from 294 individuals between the ages of 18 to $38(M=25.9)$ were collected from the public access website Connectingsingles.com. Profiles were split evenly between women $(n=152$, 52\%) and men $(n$ $=142,48 \%$ ). Concerning sexual orientation, 148 individuals identified as heterosexual (79 women and 69 men) and 146 individuals identified as homosexual (73 women and 73 men).

Participants’ racial/ethnic backgrounds included White/Caucasian ( $n=157 ; 53 \%)$, Hispanic/Latino’ ( $n=51 ; 17 \%)$, Mixed Race $(n=41 ; 14 \%)$, Black/African-American $(n=34 ; 11 \%)$, and Asian $(n=11 ; 4 \%)$. Participants’ religious affiliations included Christian/Catholic ( $n=157,53 \%)$, Spiritual/Non-religious $(n=68,23 \%)$, Other $(n=40,13 \%)$ and Agnostic/Atheist $(n=28,10 \%)$. Participants' education levels included completing high school $(n=79,27 \%)$, some college $(n=125,42 \%)$, an associates degree $(n=31,10 \%)$, a bachelors degree $(n=46,15 \%)$, and a graduate degree $(n=12,4 \%)$. The relationship type sought via the online dating site also varied among the participants, 99 (34\%), were in search of dating, 96 (33\%) were in search of a long-term relationship, 60 (20\%) were in search of a friend, activity partner, or pen pal, and 39 (13\%) were in search of an intimate encounter or short-term relationship. ${ }^{1}$
\end{abstract}

\title{
Procedure
}

Profiles were collected during the spring of 2009 from Connectingsingles.com. This website was chosen because it was public access, did not require registration, and provided the availability for users to list personal and preferred partner characteristics in narrative format. Because posting an online dating advertisement on a public access site indicates consent for review, documented consent was not sought.

Profiles were selected on the basis of gender, sexual orientation, age and location. Equal numbers of heterosexual and sexual minority men and women were obtained from searches of profiles of individuals between the ages of 18 to 38 who resided in one of the following seven metropolitan regions: San Diego, Los Angeles, San Francisco, Seattle, Chicago, New York, and Miami. In addition to these search criteria, only profiles with a complete personal and preferred partner narrative were selected.

Data collected from the profiles included participants’ reported gender, sexual orientation, racial/ethnic background, religious affiliation, educational background, type of relationship sought, and location. Personal and preferred partner narratives were recorded in their entirety for review.

\section{Coding Procedure and Consolidation of Categories}

Personal and preferred partner narratives were reviewed by five research assistants in order to identify emergent categories (see Table 1). Nine categories were identified, including: physical characteristics, sexual prowess, family and friends, honesty, kindness, fun-loving. Categories were not mutually exclusive and were each coded as present or not present in personal and preferred partner narratives. Following the identification of categories and development of a descriptive coding manual of these categories, two research assistants each coded all narratives. Adequate reliability was established for each of the categories (see Table 1).

With the goal of reducing the number of categories for clarity and to produce continuous scores on the characteristics values, the nine identified categories were subsequently reduced into overarching categories of characteristics using exploratory factor analysis with the personal characteristic data. Though somewhat controversial, exploratory factor analysis (EFA) is acceptable as a data reduction technique with dichotomous data (Kim \& Mueller, 1978). As such, we employed this statistical technique to inform a conceptual combination of categories. We conducted an initial principal-axis factor analysis to determine whether assumptions necessary for EFA were met. The Kaiser-Meyer-Olkin measure of sampling adequacy for the initial EFA was .58, an acceptable value. Bartlett's test of sphericity was significant at the .001 level, indicating that the sample size was large enough to evaluate the factor structure. Since assumptions were met, we conducted an initial principal-axis factor extraction analysis using Varimax rotation. Examination of the scree plot and eigenvalues greater than one revealed three 
distinct factors among the data. No individual characteristics cross-loaded or had factor loadings less than .30. An EFA of preferred partner characteristics yielded the same three overarching factors. Factor loadings and percent variance explained for each factor are described in Table 1.

As a result of this data reduction process, we created three conceptually meaningful continuous variables for both personal and preferred partner characteristics. Scores were summed for each of the original characteristics within each factor to create the overarching categories yielding possible scores of 0 (none of the characteristics were present in their narrative) to 3 (all three of the characteristics were present in their narrative). These three continuous variables were then used in analyses addressing our main research questions.

\section{Results}

Making use of the three overarching personal and preferred partner characteristic categories (physical, lifestyle, and personality), the following section first presents the results of a regression examining the effects of participant gender, sexual orientation, age, and desired relationship type on personal characteristics. Next, we present the results from a regression examining the effects of participant gender, sexual orientation, age, and desired relationship type on preferred partner characteristics. Lastly, we review correlations between the three personal characteristics and the three preferred partner characteristics.

\section{Demographic Differences in Personal Characteristics}

To examine the potential effects of participant gender, sexual orientation, age, and desired relationship type on personal narrative construction, three standard multiple regression analyses were conducted (one for each personal characteristic variable). These results are presented in Table 2.

There were no main effects of gender on any of the three personal characteristics variables (physical, lifestyle, and personality), when controlling for sexual orientation, age, and desired relationship type. There was a main effect of sexual orientation on the physical personal characteristic variable, controlling gender, age, and desired relationship type. Sexual -minority participants were more likely than heterosexual participants to list a "physical" characteristic in their personal narratives. There was a marginally significant effect of sexual orientation on both the lifestyle and personality variables, with heterosexual participants more likely to list these characteristics in their personal narratives. There was a main effect of age on the lifestyle variable, when controlling for gender, sexual orientation, and desired relationship type. Older participants were more likely to include this characteristic in their personal narratives. Lastly, there was a main effect of desired relationship type, when controlling for gender, sexual orientation and age, on the lifestyle variable as well, such that individual seeking more serious relationships (e.g., dating or long term) were more likely to list this characteristic that those seeking more casual relationships.

\section{Demographic Differences in Preferred Partner Characteristics}

The second set of analyses examined the potential effects of participant gender, sexual orientation, age, and desired relationship type on preferred partner narrative construction. To do so, three standard multiple regression analyses were conducted (one for each personal characteristic variable); these results are presented in Table 3.

There was a main effect of gender on the preferred partner personality variable when controlling for sexual orientation, age, and desired relationship type. Women were more likely to include these characteristics than men in their preferred partner narratives. There was a main effect of age on the personality variable, with older participants more likely to mention a personality characteristic in their preferred partner narratives. There was also a main effect of desired relationship type on the personality variable, with participants seeking more serious relationships more likely to list these characteristics. There was one marginally significant effect of sexual orientation on lifestyle, such that heterosexual participants were more likely to include these characteristics in their preferred partner narratives.

\section{Matching Personal and Preferred Partner Characteristics}

The third set of analyses included correlation analyses between personal and preferred partner characteristics to assess if characteristics participants' include in their personal narrative characteristics were associated with those that they outlined in their preferred partner narratives. Results are presented in Table 4. All three of the personal 
categories (physical, lifestyle, and personality) were significantly correlated with their corresponding preferred partner category, indicating that participants who included certain sets of characteristics in their personal narratives were subsequently likely to include similar types of characteristics in their preferred partner narratives. None of the six categories were otherwise correlated with each other.

\section{Discussion}

This exploratory study provides insights into the types of self-generated characteristics listed in online dating advertisements regarding both personal and preferred partner characteristics. Results from this study revealed at total of nine characteristics commonly described in personal and preferred partner characteristics that were reduced into three overarching categories: physical, lifestyle, and personality characteristics. Results suggest that personal and preferred partner characteristics in online dating advertisements vary most frequently by the age and desired relationship type of the individual, but also varied based on gender and sexual orientation. Lastly, supporting the matching hypothesis (Watson et al., 2004), results suggest that individuals' preferred partner characteristics are likely to match characteristics they listed in their personal narratives.

Few prior studies have explored the role of demographic characteristics beyond gender and sexual orientation of the types of personal and preferred partner characteristics listed in online dating advertisements. Interestingly, gender was not a significant predictor of any of the personal characteristics despite past research indicating differences between men and women's self presentations (Cicerello \& Sheehan, 1995; Koestner \& Wheeler, 1988). In particular, it is possible that the lack of gender-differences regarding the physical category may be more related to the specific types of physical characteristics included (e.g., short versus tall or skinny versus athletic), which were not captured in these analyses. These results also indicated that women were more likely to include personality characteristics in their preferred partner narratives. This finding can be interpreted in light of past research that has found that men frequently offer expressive qualities in ads, perhaps in anticipation that women desire these qualities (Bolig, et al., 1984). Overall, any continuing gender differences in personal ads are likely highly specific as results from this study suggest that men and women are generally offering and requesting similar types of characteristics in their online narratives.

The results of this study offer further evidence that sexual orientation is indeed an important variable, though the specific findings suggest a slightly different patterns that past research. In particular, both homosexual men and women were more likely to include physical characteristics in their advertisements and somewhat less likely to include personality and lifestyle variables, which is counter to past research which has found these patterns among homosexual men, but not women (Child, et al., 1996; Gonzales \& Meyers, 1993; Smith \& Stillman, 2002). The finding that homosexual participants more often requested short-term or casual relationships than heterosexual participants also supports findings from dating ads in print (Gonzales \& Meyers, 1993).

The results of this study also uniquely reveal the role of age in the types of characteristics male and female advertisers chose to narrate. In particular, older participants were more likely to mention lifestyle characteristics in personal narratives and personality characteristics in preferred partner narratives. This finding has implications for understanding the ways that young adults differ from 30-something adults in their dating identities, or the characteristics they think might be attractive to potential partners. For example, while physical characteristics are important to those in all age groups, it is not until later in life that lifestyle and personality characteristics seem important enough to include in one's profile.

An examination of the role of desired relationship type revealed that this variable also was associated with certain personal and preferred partner characteristics. Namely, those seeking short-term intimate encounters were more likely to mention sexual prowess and physical characteristics, while dating or long-term relationship seeking advertisers were more likely to mention personal competence, an active or cultured lifestyle and a desire for niceness and honesty. These results complement those of Buunk, et al. (2002). Overall, these results indicate that individuals' vary their presentation of self and preferred partner characteristics depending on the relationship type they were advertising, suggesting that romantic identities are related to desired relational outcomes.

Consistent with limited past research (Miller, et al., 2000; Rowat, et al., 1999), the results from this study suggest that the categories of characteristics individuals' include in personal narratives tend to also be included in preferred partner narratives. For all three of the characteristics in this study, the descriptive inclusion of a given characteristic 
in a participant's personal narrative was more likely to also be supplemented with that given characteristic in her or his preferred partner narrative. Regarding the physical characteristics, this finding best suggests that individuals who stipulate physical or sexual interests in their partners are generally willing to offer their own in a personal narrative. These correlations also suggest that individuals seek dating partners with similar personalities and lifestyles to those they purport to have themselves. Conversely, this can also indicate that if a particular characteristic is desired in a partner, individuals' anticipate that presenting it as a personal characteristic might attract that kind of mate. Overall, the matching hypothesis is supported by these findings (Watson et al., 2004).

\section{Conclusion}

Despite the novel information garnered from these results, there are several limitations to this study. First, the information available regarding participant's backgrounds was limited to that which was noted on the personal ad website, necessarily limiting the demographic variables represented in the study. Additionally, in order to access profiles without participants' consent, it was necessary to use a publicly accessible website, which may have a clientele not representative of other online dating websites. Furthermore, individuals who post on online dating websites may not be representative of the broader young adult dating population, thus limiting the generalizability of these findings. Future research could contact advertisers directly to assess a broader array of variables and to assess individuals who post on more populated private dating services, such as Match.com or EHarmony.com. Future research should further examine the gender differences in matching characteristics to better understand the gender differences revealed in this study. Lastly, because this study was exploratory in its derivation of categories and review of both personal and preferred partner characteristics, replication is needed.

The evidence of a pattern of characteristics included in participant-generated narratives identified certain physical characteristics, personality qualities, and lifestyles that individuals view as important to their dating identities and those of their preferred dating partners. These characteristics do indeed vary based on a variety of demographic variables, as well the type of relationship individual's are seeking, indicating variation in the prominence each typical characteristic is given. Understanding that age, sexual orientation, and gender impact the types of characteristics individuals incorporate into their dating identities is useful for our understanding of young adult romantic relationship development. Finally, the inclusion of matching characteristics indicates support for individuals seeking out partners with similar characteristics. 


\section{References}

Arvidsson, A. (2006). 'Quality singles': Internet dating and the work of fantasy. New Media and Society 8, 671-690.

Bolig, R., Stein, P. J., and McKenry, P. C. (1984). The self-advertisement approach to dating: Male-female differences. Family Relations 33, 587-592.

Buunk, B.P., Dijkstra, P., Fetchenhauer, D., and Kenrick, D.T. (2002). Age and gender differences in mate selection criteria for various involvement levels. Personal Relationships 9, 271-278.

Kenrick, D.T., Keefe, R.C., Bryan, A., Barr, A., and Brown, S. (1995). Age preferences and mate choice among homosexuals and heterosexuals: A case for modular psychological mechanisms. Journal of Personality and Social Psychology 69, 1166-1172.

Child, M., Low, K., McCormick, C., and Cocciarella, A. (1996). Personal advertisements of male-to-female transsexuals, homosexual men, and heterosexuals. Sex Roles 34, 447-455.

Cicerello, A., and Sheehan, E.P. (1995). Personal advertisements: A content analysis. Journal of Social Behavior and Personality 10, 751-756.

Coupland, J. (2000). Past the "perfect kind of age”? Styling selves and relationships in over-50s dating advertisements. Journal of Communication 50, 9-30.

Ellison, N., Heino, R., and Gibbs, J. (2006). Managing impressions online: Self-presentation processes in the online dating environment. Journal of Computer-Mediated Communication 11, 415-441.

Gibbs, J. L., Ellison, N. B., and Heino, R. D. (2006). Self presentation in online personals: The role of anticipated future action, self-disclosure, and perceived success in internet dating. Communication Research 33, 153177.

Gonzalez, M.H., and Meyers, S.A. (1993). "Your mother would like me”: Self-presentation in the personal ads of heterosexual and homosexual men and women. Personality and Social Psychology Bulletin 19, 131-142.

Hardey, M. (2004). Mediated relationships. Information, Communication and Society 7, 207-222.

Harrison, A.A., and Saeed, L. (1977). Let's make a deal: An analysis of revelations and stipulations in lonely-hearts advertisements. Journal of Personality and Social Psychology 35, 257-264.

Hatala, M., Milewski, K., and Baack, D. (1999). Downloading love: A content analysis of internet personal advertisements placed by college students. College Student Journal 33, 124-130.

Hatala, M. N. and Prehodka, J. (1996). Content Analysis of Gay Male and Lesbian Personal Advertisements. Psychological Reports 78, 371-374.

Jagger, E. (2001). Marketing Molly and Melville: Dating in a postmodern, consumer society. Sociology 35, 39-57.

Jagger, E. (2005). Is thirty the new sixty? Dating, age and gender in a postmodern, consumer society. Sociology 39, 89-106.

Kim, J., \& Mueller, C. W. (1978). Factor Analysis: Statistical methods and practical issues. Thousand Oaks, CA: Sage Publications, Quantitative Applications in the Social Sciences Series, No. 14.

Koestner, R., and Wheeler, L. (1988). Self-presentation in personal advertisements: The influence of implicit notions of attraction and role expectations. Journal of Social and Personal Relationships 5, 149-160.

Matthews, T. D. (1999). A World-Wide Web-based research project. The Teaching of Psychology 26, $227-230$.

Miller, E., Smith, J. E., and Trembath, D. L. (2000). The 'skinny' on body size requests in personal ads. Sex Roles 43, 129-141.

Online Dating Magazine. (2007). Online dating magazine media center: Abbreviated online dating facts and stats. Retrieved October 2009, from http://www.onlinedatingmagazine.com/mediacenter/onlinedatingfacts.html.

PRWeb. (2009). Half of Americans Know Someone Who Has Dated a Person They Met Online, According to New Study from People Media. Retrieved from, http://www.prweb.com/ releases/2009/08/prweb2758114.htm.

Rajecki, D. W., Bledsoe, S. B., and Rasmussen, J. L. (1991). Successful personal ads: Gender differences and similarities in offers, stipulations, and outcomes. Basic and Applied Social Psychology 12, 457-469.

Rowat, W. C., Cunningham, M. R., and Druen, P. B. (1999). Lying to Get a Date: The Effect of Facial Physical Attractiveness on the Willingness to Deceive Prospective Dating Partners. Journal of Social and Personal Relationships 16, 209-223.

Smith, C. A., and Stillman, S. (2002). What do women want? The effects of gender and sexual orientation on the desirability of physical attributes in the personal ads of women. Sex Roles 46(9/10), 337-342.

Thorne, A., and Coupland, J. (1998). Articulations of same-sex desire: Lesbian and gay male dating advertisements. Journal of Sociolinguistics 2, 233-257.

Toma, C. L., Hancock, J. T., and Ellison, N. B. (2008). Separating fact from fiction: An examination of deceptive self-presentation in online dating profiles. Personality and Social Psychology Bulletin 34,1023-1036. 
NOTICE: This is the author's version of a work accepted for publication by Elsevier. Changes resulting from the publishing process, including peer review, editing, corrections, structural formatting and other quality control mechanisms, may not be reflected in this document. Changes may have been made to this work since it was submitted for publication. The definitive version has been published in Computers in Human Behavior, Volume 26, Issue 5, 2010. DOI: 10.1016/j.chb.2010.02.002

Watson, D., Klohnen, E. C., Casillas, A., Nus Simms, E., Haig, J., and Berry, D., (2004). Match makers and deal breakers: Analyses of assortative mating in newlywed couples. Journal of Personality 72, 1029-1068.

Whitty, M. T. (2008). Revealing the 'real' me, searching for the 'actual' you: Presentations of self on an internet dating site. Computers in Human Behavior 24, 1707-1723. 
NOTICE: This is the author's version of a work accepted for publication by Elsevier. Changes resulting from the publishing process, including peer review, editing, corrections, structural formatting and other quality control mechanisms, may not be reflected in this document. Changes may have been made to this work since it was submitted for publication. The definitive version has been published in Computers in Human Behavior, Volume 26, Issue 5, 2010. DOI: 10.1016/j.chb.2010.02.002

\section{Notes}

1. Desired relationship type was significantly associated with sexual orientation; homosexual participants selected more casual relationships than heterosexual participants, $t(292)=3.75, p<.001$. Gender and age were not associated with desired relationship type. 
Table 1

Categories of characteristics coded from personal and preferred narratives.

\begin{tabular}{cccccc}
\hline Coding & Cohen's & Percent & Factor & Brief Description of Coding Category & Coding Category Examples from \\
Category & Kappa & Present & Loading & & Narratives Collected
\end{tabular}

Factor 1: Lifestyle (20.42\% of variance)

Active $\quad .85 / .80 \quad 34 \% / 11 \%$

Culture

$.88 / .79 \quad 42 \% / 20 \%$

Family

$.88 / .77 \quad 24 \% / 9 \%$

Factor 2: Personality (15.63\% of variance)
Honesty
$.87 .87 \quad 16 \% / 26 \%$

.622
Expressing preference for or personally engaging in athletically demanding

activities, outdoor ventures, sporting events, summer." or traveling.

Expressing preference for or personally enjoying intellectual or artistic endeavors, for example, museums, music, art, film, theatre, or culinary arts.

Expressing preference for or personally having priority in familial and friendship ties, desire to parent children, caring for pets, or quality time with family.

Expressing preference for or personally being trustworthy, sincere, frank or straightforward.
"I love anything outdoors." And "I do

Triathlons and Biathlons every

"I love to paint everything from canvases to furniture." And "I'm passionate about great film, good music, photography \& travel." "I am looking for someone with or without kids, but will be accepting of mine." And "Looking for someone who likes animals."

"I am looking for a lady who is honest and respects me." And "Someone who will always be there for me and doesn't lie or cheat." 
NOTICE: This is the author's version of a work accepted for publication by Elsevier. Changes resulting from the publishing process, including peer review, editing, corrections, structural formatting and other quality control mechanisms, may not be reflected in this

document. Changes may have been made to this work since it was submitted for publication. The definitive version has been published in Computers in Human Behavior, Volume 26, Issue 5, 2010. DOI: 10.1016/j.chb.2010.02.002

$$
.70 .7251 \% / 43 \%
$$

Fun-loving

Kind $.76 / 67 \quad 23 \% 28 \%$

Factor 3: Physical (12.37\% of variance)

Physicality $\quad .71 / .69 \quad 21 \% / 29 \%$

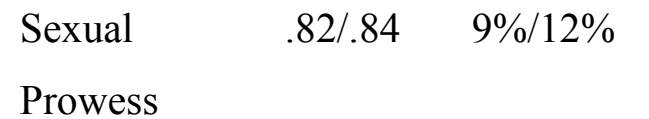

Nightlife $\quad .78 / .62 \quad 16 \% / 5 \%$ .601
Expressing preference for or personally being compassionate, empathetic, or nonjudgmental.

Expressing preference for or personally having a specified physical makeup, a certain height, muscularity, or attractiveness.

Expressing preference for or personally having traits of a sexual nature, physical endowments, sexual interests and proclivities, and sexual abilities.

Expressing preference for or personally being playful, carefree, funny or likeable.

Expressing preference for or personally spending time in being social in bars, clubs, or casinos.
"I am a loving person who is down for pretty much anything, outgoing, and love to have fun and party." And "I want someone funny, who'll motivate me and keep me amused."

"I am a person who gives everyone a change without judgment." And "I am easygoing and laidback, nice, sweet and caring."

"I'm 5'2 and 137 lbs." And "I'm a very handsome black male. I have a stocky beefy husky build...carry myself pretty well."

"I am a crazy sexual girl looking for another girl to please me." And "just a chill girl that can have fun...that likes it ruff and wild [in] the bedroom." "I like going to Vegas." And "I like to have fun, go clubbing, and go to lots of parties.

Note. Cohen's kappas and percent present are for personal characteristics/preferred partner characteristics. 


\section{Table 2}

Multiple regression analyses predicting personal characteristics.

Physical: $\mathrm{R}^{2}=.070, \mathrm{~F}(4,294)=5.44, p<.001$

Variable

$\mathrm{B}$

SE B

Beta

Gender

.090

.072

.070

Sexual Orientation

.313

.078

$.246 * * *$

Age

.001

.008

.008

Relationship Type

$-.027$

.033

$-.046$

Lifestyle: $\mathrm{R}^{2}=.070, \mathrm{~F}(4,294)=5.40, p<.001$

Variable

B

SE B

Beta

Gender

.114

.114

.057

Sexual Orientation

.123

$-.120 \dagger$

Age

.022

.011

$.125 *$

Relationship Type

.127

.053

$.141 *$

Personality: $\mathrm{R}^{2}=.019, \mathrm{~F}(4,294)=1.38, p=.24$

Variable

B

SE B

Beta

Gender

.100

.106

.055

Sexual Orientation

$-.224$

.114

$-.123 \dagger$

Age

$-.002$

.010

$-.010$

Relationship Type

.009

.049

.011

Note. Personal and preferred partner characteristics are all continuous variables ranging from 0

(none present) to 3 (all three categories present). Gender $=1$ for women, 0 for men. Sexual

orientation $=1$ for homosexual, 0 for heterosexual. Relationship type $=0$ (casual relationship) to

3 (long term relationship). $\dagger p<.10, * p<.05, * * p<.01, * * * p<.001$ 
Table 3

Multiple regression analyses predicting preferred partner characteristics.

Physical: $\mathrm{R}^{2}=.021, \mathrm{~F}(4,294)=1.53, p=.19$

Variable

$\mathrm{B}$

SE B

Beta

Gender

.052

.072

.043

Sexual Orientation

.166

.077

.095

Age

.007

.007

.065

Relationship Type

$-.032$

.033

$-.057$

Lifestyle: $\mathrm{R}^{2}=.021, \mathrm{~F}(4,294)=1.53, p=.19$

Variable

B

SE B

Beta

Gender

.088

.077

.066

Sexual Orientation

$-.159$

.083

$-.120 \dagger$

Age

.002

.007

.017

Relationship Type

$-.030$

.036

$-.051$

Personality: $\mathrm{R}^{2}=.049, \mathrm{~F}(4,294)=3.67, p=.006$

Variable

B

SE B

Beta

Gender

.193

.106

$.134 *$

Sexual Orientation

.020

.114

.011

Age

.017

.010

$.133 *$

Relationship Type

.142

.049

$.170 *$

Note. Personal and preferred partner characteristics are all continuous variables ranging from 0

(none present) to 3 (all three categories present). Gender $=1$ for women, 0 for men. Sexual

orientation $=1$ for homosexual, 0 for heterosexual. Relationship type $=0$ (casual relationship) to

3 (long term relationship). $\dagger p<.10, * p<.05$ 
NOTICE: This is the author's version of a work accepted for publication by Elsevier. Changes resulting from the publishing process, including peer review, editing, corrections, structural formatting and other quality control mechanisms, may not be reflected in this document. Changes may have been made to this work since it was submitted for publication. The definitive version has been published in Computers in Human Behavior, Volume 26, Issue 5, 2010. DOI: 10.1016/j.chb.2010.02.002

\section{Table 4}

Intercorrelations of personal and preferred partner characteristics.

\begin{tabular}{lccc}
\hline Personal & \multicolumn{3}{c}{ Preferred Partner } \\
& Physical & Lifestyle & Personality \\
\hline Physical & $.290^{* * *}$ & -.077 & -.095 \\
Lifestyle & - & $.236^{* * *}$ & .055 \\
Personality & - & - & $.131^{*}$ \\
\hline
\end{tabular}

Note. $N=294 . * p<.05, * * * p<.001$ 